\title{
Biliary tract cancers in Cote-d'Or (France): incidence and natural history
}

\author{
P RENARD, MC BOUTRON, J FAIVRE, C MILAN, L BEDENNE, P HILLON, AND \\ C KLEPPING
}

From the Registre des Tumeurs Digestives, Faculté de Médecine, 7 boulevard Jeanne d'Arc, 21033 Dijon, France

SUMMARY The registry of digestive tract tumours established for the department of Cote-d'Or (France) was used to study the epidemiological characteristics and the natural history of biliary tract cancers. Age standardised incidence rates for gallbladder cancers were $2 \cdot 7 / 100000$ for women and $0 \cdot 9 / 100000$ for men. The corresponding rates for extrahepatic bile duct cancers were $0 \cdot 5 / 100000$ and $1 \cdot 7 / 100000$, and for ampulla of Vater cancer $0 \cdot 3 / 100000$ and $0 \cdot 3 / 100000$. The three cancers differ in their descriptive epidemiology and should be considered separately in epidemiological analytical investigations. The incidence of each of the three diseases increased with age, and cancers of known histological type were mainly adenocarcinomas. Some gallbladder cancers were undifferentiated or squamous cell carcinomas. There was no significant variation in incidence for gallbladder cancer and extrahepatic bile duct cancer over the eight years of the study. The association with gallstones was frequent in gallbladder cancer: $70.5 \%$ compared to $13.0 \%$ in other biliary tract cancers $(<0 \cdot 001)$. Although the association of gallbladder cancer with gallstones is frequent, few patients with cholelithiasis experience development of a gallbladder cancer. It is necessary to identify among patients with gallstones a subgroup at high risk of gallbladder cancer in whom prophylactic surgery might be justified. Biliary tract cancers are seldom diagnosed early: lymph nodes or visceral metastases were present in $77 \%$ of gallbladder cancers, in $83 \%$ of extrahepatic bile duct cancers, and in $55 \%$ of ampulla of Vater cancers at the time of diagnosis. The corresponding resectability rates were $46 \cdot 1 \%, 11.9 \%$, and $38.9 \%$. The five-year overall survival rates were $2.9 \%$ for gallbladder cancer, $0 \%$ for extrahepatic bile duct cancer, and $18.3 \%$ for ampulla of Vater cancer. The corresponding five-year survival rates after surgery for cure were $10 \cdot 3 \%, 0 \%$, and $35 \cdot 7 \%$. Biliary tract cancers still represent a great therapeutic challenge.

Little information on the epidemiology of biliary tract cancers is available. Prior to the 7th edition of the International Classification of Diseases these cancers were considered together with primary liver cancers. Many cancer registries present biliary tract cancers as a unit, although the most recent versions of the International Classification of Diseases distinguish the different sites of biliary tract cancers: gallbladder, extrahepatic bile ducts, and ampulla of Vater. There have been only three previous reports which considered separately the three localisations of biliary tract cancers. ${ }^{1-3}$ Most of the data regarding the distribution and the characteristics of these cancers are based on surgical or necropsy experience. This study was undertaken to provide detailed data on the descriptive epidemiology of biliary tract cancers in the well defined population of the department of Cote-
d'Or, France, and to provide information on the natural history of these cancers.

\section{Patients and methods}

A population-based cancer registry, limited to digestive tract cancers, covers the resident population of the Cote-d'Or (477952 according to the 1982 census). This study included all cases of biliary tract cancers reported to the registry between 1 January 1976 and 31 December 1983. Information was collected from pathology laboratories, university hospitals, local hospitals, surgeons, gastroenterologists, general practitioners, social security offices, and death certificates. Because of the active cooperation of the medical profession in the department, it was assumed that nearly all newly 
diagnosed cancers had been registered. The diagnosis was histologically confirmed in $72.7 \%$ of cases. In the remaining cases it was based on surgical or necropsy findings $(17.6 \%)$ or on the cohesion of diagnosis tools: ultrasonography and/or computed tomography, and/or endoscopic retrograde cholangiography $(9 \cdot 7 \%)$. The site was coded according to the International Classification of Diseases for Oncology. The operation was considered as curative if the primary tumour had been removed with no evidence of distant metastases. Operative mortality was defined as death occurring within $\mathbf{3 0}$ days after surgery. The extent of the disease at the time of diagnosis was based on hospital records and reports from pathology laboratories. The extent was imprecise for cases in which metastases had not been observed at diagnosis and for which no operation had been performed.

The incidence rates, calculated on an annual basis, were an average of eight years' registration. Population data used in calculating incidence rates were based on estimates of the Cote-d'Or population by age and sex calculated annually by the Institut National da la Statistique et des Etudes Economiques (INSEE). Age standardised incidence rates were calculated using the world standard population. For the computation of rates in urban and rural areas, the so-called indirect standardisation method (SIR) was applied. To describe time trends in cancer incidence, an exponential curve of the form $y=a e^{b t}$ was fitted to the annual incidence rates by means of a regression technique. It allows for a direct interpretation of the average annual percent change. Survival rates were calculated using the life table method. Corrected survival rates were the ratio of the observed survival rates and of the expected survival rates derived from the French population life tables. Follow-up data were available in December 1985 for $99.5 \%$ of the patients. Survival curves were compared using the logrank test.

\section{Results}

A total of 216 biliary tract cancers were diagnosed among Cote-d'Or residents in the period 1976-83. They represented $3 \cdot 2 \%$ of digestive tract cancers in men and $9.6 \%$ in women. The crude annual incidence rate was $3 \cdot 7 / 100000$ for men and $7 \cdot 7 / 100000$ for women. The corresponding age standardised rates were 2.9 and $3 \cdot 5$.

Incidence rates by sex for the different sites of biliary tract cancers are listed in table 1 . In men, extrahepatic bile duct cancers were the most common localisation of biliary tract cancers followed by cancers of the gallbladder. In women, cancers of the gallbladder prevailed over cancers of the extrahepatic bile ducts. Cancers of the ampulla of Vater were third in both sexes. There was a female predominance for gallbladder cancers and a male predominance for extrahepatic bile duct cancers.

The mean age of the patients at the time of diagnosis was lower in men than in women for all localisations (table 1). Age specific incidence rates for the three localisations of biliary tract cancers are given in the figure. Incidence rates increased progressively with advancing age. They grew more rapidly in women for gallbladder and ampulla of Vater cancers, and in men for extrahepatic bile duct cancers. Biliary tract cancers

Table 1 Mean age at diagnosis and incidence by sex and location of biliary tract cancers

\begin{tabular}{|c|c|c|c|c|c|c|}
\hline \multirow[b]{2}{*}{ Cancer } & \multicolumn{2}{|c|}{ Number of cases } & \multicolumn{2}{|c|}{ Age at diagnosis } & \multicolumn{2}{|c|}{ Age standardised rates* } \\
\hline & Men & Women & Men & Women & Men & Women \\
\hline Galbladder & 23 & 116 & $70 \cdot 3 \pm 10 \cdot 3$ & $74 \cdot 6 \pm 9 \cdot 6$ & 0.9 & $2 \cdot 7$ \\
\hline Extrahepatic bile duct & 39 & 20 & $69 \cdot 8 \pm 10 \cdot 8$ & $75 \cdot 4 \pm 9 \cdot 7 \dagger$ & 1.7 & 0.5 \\
\hline Ampulla of Vater & 7 & 11 & $64 \cdot 6 \pm 12 \cdot 3$ & $72 \cdot 4 \pm 11 \cdot 3$ & 0.3 & $0 \cdot 3$ \\
\hline
\end{tabular}

Incidence per 100000

$t \mathrm{p}<0.005$

Table 2 Relative incidence of biliary tract cancers in urban and rural areas by localisation*

\begin{tabular}{|c|c|c|c|c|c|c|}
\hline & \multicolumn{2}{|c|}{ Gallbladder } & \multicolumn{2}{|c|}{ Extrahepatic bile ducts } & \multicolumn{2}{|c|}{ Ampulla of Vater } \\
\hline & Men & Women & Men & Women & Men & Women \\
\hline Urban & 104 & 83 & 87 & 68 & 100 & 108 \\
\hline Rural & 95 & 125 & 117 & 146 & 99 & 88 \\
\hline
\end{tabular}

\footnotetext{
* Standardised incidence ratio
} 


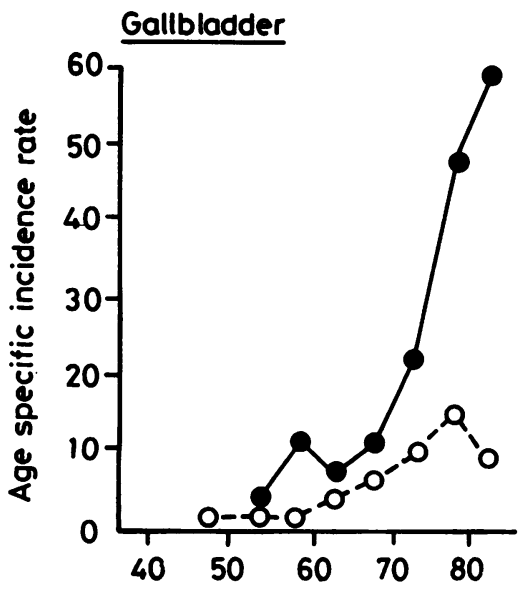
Extra hepatic bile ducts
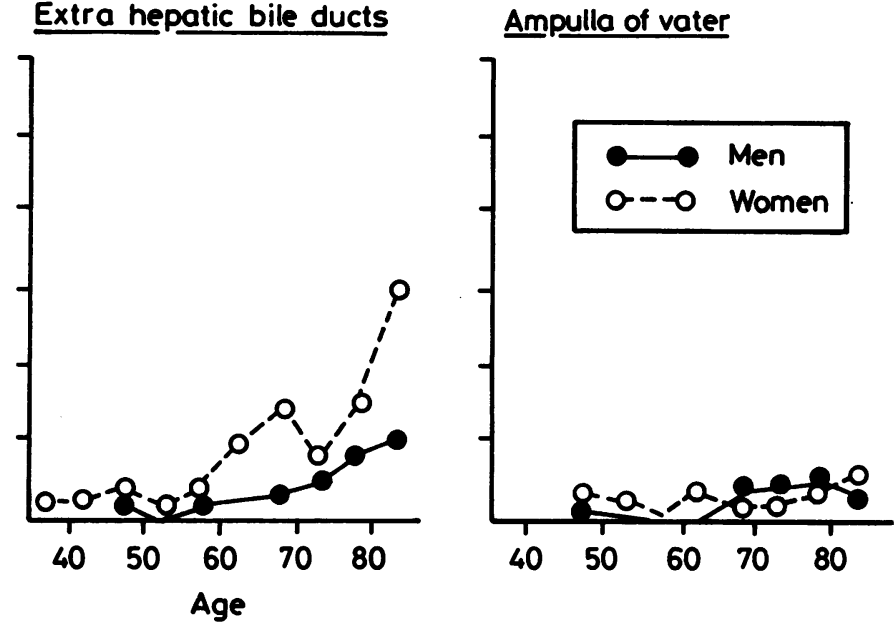

Age specific incidence rate by subsite and sex for biliary tract cancers

were rare before age 55 in both sexes $(6.0 \%$ of the cases). In men, the incidence rates were similar in urban and rural areas for the three localisations of biliary tract cancers (table 2). In women, there was a slight rural predominance for gallbladder and extrahepatic bile duct cancers (NS).

The mean annual variation for gallbladder cancer was $+11.8 \% \pm 20.4 \%$ in men and $-3.8 \% \pm 7.7 \%$ in women (NS). The corresponding variations for extrahepatic bile duct cancers were $-1.4 \% \pm 20 \%$ and $+4 \cdot 2 \% \pm 21 \cdot 7 \%$ (NS).

A histological diagnosis was obtained in 112 gallbladder cancers $(80.6 \%)$, in 31 extrahepatic bile duct cancers $(52.5 \%)$, and in 14 ampulla of Vater cancers $(\mathbf{7 7} \cdot 8 \%)$. Among gallbladder cancers, 94 (83.9\%) were adenocarcinomas, $14 \quad(10.4 \%)$ undifferentiated carcinomas, $3(2 \cdot 7 \%)$ squamous cell carcinomas, and $1(0.9 \%)$ a sarcoma. All extrahepatic bile duct cancers were adenocarcinomas. Ampulla of Vater cancers included $13(92.9 \%)$ adenocarcinomas and 1 carcinoid tumour.

Gallstones were recorded in $8(13.6 \%)$ extrahepatic bile duct cancers, in $2(11 \cdot 1 \%)$ ampulla of Vater cancers, and in $98(70.5 \%)$ gallbladder cancers. Gallstones were more frequent in gallbladder cancers than in other biliary tract cancers $(p<0.001)$. No case arose in congenital cysts, sclerosing cholangitis or ulcerative colitis.

Treatment of biliary tract cancers varied according to the site of the cancer (table 3). Resection, either curative or palliative, was possible in $46.1 \%$ of gallbladder cancers, in $11.9 \%$ of extrahepatic bile duct cancers, and in $38.9 \%$ of ampulla of Vater cancers. The operative mortality was $12.5 \%$ after curative resection $(10.9 \%$ for gallbladder cancers, $25.0 \%$ for extrahepatic bile duct cancers, $14.3 \%$ for ampulla of
Table 3 Treatment of biliary tract cancers by site

\begin{tabular}{|c|c|c|c|c|c|c|}
\hline \multirow[b]{2}{*}{ Curative resection } & \multicolumn{2}{|c|}{ Gallbladder } & \multicolumn{2}{|c|}{$\begin{array}{l}\text { Extrahepatic } \\
\text { bile ducts }\end{array}$} & \multicolumn{2}{|c|}{$\begin{array}{l}\text { Ampulla } \\
\text { of Vater }\end{array}$} \\
\hline & 29 & $20.9 \%$ & 4 & $6.8 \%$ & 7 & $38.9 \%$ \\
\hline Palliative resection & 35 & $25 \cdot 2 \%$ & 3 & $5 \cdot 1 \%$ & - & \\
\hline Bypass operation & 16 & $11 \cdot 5 \%$ & 30 & $50 \cdot 8 \%$ & 8 & $44.4 \%$ \\
\hline Exploratory laparotomy & 36 & $25 \cdot 9 \%$ & 17 & $28 \cdot 8 \%$ & - & \\
\hline Non-surgical treatment & 23 & $16 \cdot 5 \%$ & 5 & $8 \cdot 5 \%$ & 3 & $16.7 \%$ \\
\hline
\end{tabular}

Vater cancers). It was $34 \cdot 2 \%$ after palliative resection $31.5 \%$ after bypass operation, and $66.0 \%$ after exploratory laparotomy. Among non-surgically? treated patients, $77 \cdot 4 \%$ died during the month following diagnosis.

The stage of diagnosis of biliary tract cancers by site is given in table 4. Cancers limited to the organ were rare. Lymph nodes or visceral metastases were present at the time of diagnosis in $77 \%$ of gallbladder cancers, in $83 \%$ of extrahepatic bile duct cancers, and in $55 \%$ of ampulla of Vater cancers.

The overall observed survival rates were $14.4 \%$ at one year and $2.9 \%$ at five years. The corresponding corrected survival rates were $19.0 \%$ and $4.9 \%$. The

Table 4 Stage diagnosis of biliary tract cancers by site

\begin{tabular}{|c|c|c|c|c|c|c|}
\hline \multirow[b]{2}{*}{ Limited to the organ } & \multicolumn{2}{|c|}{ Gallbladder } & \multicolumn{2}{|c|}{$\begin{array}{l}\text { Extrahepatic } \\
\text { bile ducts }\end{array}$} & \multicolumn{2}{|c|}{$\begin{array}{l}\text { Ampulla } \\
\text { of Vater }\end{array}$} \\
\hline & 22 & $15 \cdot 8 \%$ & 4 & $6.8 \%$ & 6 & $33 \cdot 3 \%$ \\
\hline $\begin{array}{l}\text { Locoregional } \\
\text { extension or } \\
\text { positive nodes }\end{array}$ & 33 & $23 \cdot 7 \%$ & 31 & $52.5 \%$ & 8 & $44.4 \%$ \\
\hline Distant metastases & 74 & $53 \cdot 2 \%$ & 18 & $30 \cdot 5 \%$ & 2 & $11 \cdot 1 \%$ \\
\hline Not precise & 10 & $7 \cdot 2 \%$ & 6 & $10 \cdot 2 \%$ & 2 & $11 \cdot 1 \%$ \\
\hline
\end{tabular}


survival curve for ampulla of Vater cancers was significantly better than the curves for the other localisations of biliary tract cancers $(p<0 \cdot 001)$. The five-year observed survival rates were $2.9 \%$ for gallbladder cancers, $0 \%$ for extrahepatic bile duct cancers, and $18.3 \%$ for ampulla of Vater cancers. The corresponding five-year survival rates after surgery for cure were $10 \cdot 3 \%, 0 \%$, and $35 \cdot 7 \%$.

\section{Discussion}

Through this use of the cancer registry data, the frequency of biliary tract cancers could be assessed with respect to other digestive tract cancers. They represented $5.9 \%$ of the 3668 registered cases. Among biliary tract cancers, $64.4 \%$ originated in the gallbladder, $27.3 \%$ in the extrahepatic bile ducts, and $8.3 \%$ in the ampulla of Vater.

One of the important uses of cancer registries is to permit international comparisons. The Cote-d'Or is in the intermediate range for gallbladder cancer with rates similar to those reported among West European cancer registries. Incidence rates were three to sevenfold lower in the Cote-d'Or than in the high risk populations such as Indian or Spanish Americans and East Europeans. ${ }^{1}$ High rates of extrahepatic bile duct cancer were observed in Japan. ${ }^{1}$ The incidence of extrahepatic bile duct cancer was also found to be relatively high in the Cote-d'Or, particularly among men. There is little difference in incidence among ampulla of Vater cancers.

In the Cote-d'Or, $83.5 \%$ of patients with gallbladder cancers were women, while $66.1 \%$ of extrahepatic bile duct cancers were in men. Gallbladder cancer was the most common biliary tract cancer everywhere and was more frequent in women than in men. ${ }^{13}$ Cancer of the extrahepatic bile ducts came next and showed a male predominance. Cancer of the ampulla of Vater was the least common and occurred equally in both sexes.

Age was the strongest risk indicator for all biliary tract cancers. They became relatively frequent after age 50, and incidence rates increased with advancing age, although most rapidly with gallbladder cancer and least rapidly with ampulla of Vater cancer. ${ }^{1}$

There is a high frequency of gallstones in cases of gallbladder cancer. This finding is in accord with published data. ${ }^{24}$ As well as gallbladder cancer, cholelithiasis shows a high female/male ratio, an increasing incidence with age, and identical variations among countries and ethnic groups. ${ }^{56}$ These similarities suggest that one of these disorders may cause the other, or that they may have a common cause. Nevertheless few persons with stones develop gallbladder cancer. ${ }^{7-10}$ They are mainly elderly women with a short history of symptoms. A recent study has underlined the fact that the risk of gallbladder cancer in untreated subjects with gallstones is heterogeneous, depending on race, sex and duration of the presence of gallstones. ${ }^{6}$ It has been estimated in Sweden that the 20 -year cumulative risk of gallbladder cancer varied from $0.26 \%$ in men to $0.50 \%$ in women, and that the number of cholecystectomies needed to prevent one gallbladder cancer was 384 in men and 200 in women. ${ }^{6}$ The risk of prophylactic cholecystectomy would be likely to outweigh any benefits from cancer prevention. Among patients with cholelithiasis it is necessary to identify high risk patients in whom prophylactic cholecystectomy might be justified. Data from a case control study suggested an association of gallbladder cancer with large gallstones. ${ }^{11}$ The odds ratio was 10:1 for stones of $3 \mathrm{~cm}$ or larger. If this result is confirmed, prophylactic cholecystectomy might be indicated in these patients. There is no known predisposing or aetiological factor for cancer of the ampulla of Vater.

A recognised relation exists between extrahepatic bile duct cancers, ulcerative colitis, congenital cysts of the biliary tract, and sclerosing cholangitis. These diseases are rare, and in our study no case has arisen during the course of eight years among such patients.

It appears that the three localisations of biliary tract cancers differ in their geographic distribution, their sex ratio, and the frequency of gallstones. The epidemiological differences among the three forms of biliary tract cancers suggest that the aetiologies of these tumours are different. They must be described separately and should be assessed independently when possible disease aetiologies are being investigated.

Biliary tract cancers are rarely curable when discovered. Their prognosis is extremely poor. Extrahepatic bile duct cancers were the most difficult to treat. Resection was not often possible, and there was no survival of more than 3.5 years. In nearly $80 \%$ of the patients the only possible operation was a bypass or exploratory laparotomy. The experience with chemotherapeutic agents in the treatment of biliary tract cancers is small and the results discouraging. ${ }^{12}$ Potential benefits of postoperative external radiotherapy after decompression have been suggested. ${ }^{13}$ Clinical experience has been reported at operation or by percutaneous techniques ${ }^{14}$ and with intraoperative radiotherapy. ${ }^{15}$ Whether or not these techniques will have an impact on survival remains to be seen. Clearly, new approaches to the management of biliary tract cancers need to be found.

We are grateful to Cote-d'Or practitioners for reporting their cases to the cancer registry, particularly the pathologists Drs R Michiels, P Dusserre, and $\mathbf{H}$ Bastien. 
Correspondence and requests for reprints: Pr J Faivre, Faculté de Médecine, 7 Boulevard Jeanne d'Arc, 21033 Dijon, France.

\section{References}

${ }^{1}$ Waterhouse J, Muir C, Correa P, Powell J. Cancer incidence in five continents, vol IV. IARC Scientific Publications, No. 42, Lyon, 1982.

2 Menck HR, Mack TM. Incidence of biliary tract cancer in Los Angeles. Natl Cancer Inst Monogr, 1982; 62: 95-9.

${ }^{3}$ Strom BL, Hibberd PL, Soper KA, Stolley PD, Nelson WL. International variations in epidemiology of cancers of the extrahepatic biliary tract. Cancer Res 1985; 45: 5165-8.

${ }^{4}$ Maram ES, Ludwig J, Kurland LT, Brian DD. Carcinoma of the gallbladder and extrahepatic biliary ducts in Rochester, Minnesota, 1935-1971. Am J Epidemiol 1979; 109: 152-7.

${ }^{5}$ Sampliner RE, Bennett PH, Comess LJ, Rose FA, Burch TA. Gallbladder disease in Pima indians. Demonstration of high prevalence and early onset by cholecystography. N Engl J Med 1970; 283: 1358-64.
${ }^{6}$ Lowenfels AB, Lindstrom CG, Conway MJ, Hastings PR. Gallstones and risk of gallbladder cancer. JNCI 1985; 75: 77-80.

${ }^{7}$ Diehl AK. Silent gallstones: The doctor's dilemma. Compr Ther 1982; 8: 62-8.

${ }^{8}$ Bateson MC. Gallbladder disease and cholecystectomy rate are independently variable. Lancet 1984; ii: 621-4.

${ }^{9}$ Godfrey PJ, Bates T, Harrison M, King MB, Padley NR. Gallstones and mortality: a study of all gallstone related deaths in a single health district. Gut 1984; 25: 1029-33.

${ }^{10}$ Gracie WA, Ransohoff DF. The natural history of silent gallstones. The innocent gallstone is not a myth. $N$ Engl J Med 1982; 307: 798-800.

${ }^{11}$ Diehl AK. Gallstone size and the risk of gallbladder cancer. JAMA 1983; 250: 2323-6.

12 Falkson G, MacIntyre JM, Moertel CG. Eastern Cooperative Oncology Group Experience with chemotherapy for inoperable gallbladder and bile duct cancer. Cancer 1984; 54: 965-9.

${ }^{13}$ Herskovic A, Heaston D, Engler MJ, Fishburn RI, Jones RS, Noell KT. Irradiation of biliary carcinoma. Radiology 1981; 139: 219-22.

14 Todoroki T, Iwasaki Y, Okamura T, et al. Intraoperative radiotherapy for advanced carcinoma of the biliary system. Cancer 1980; 46: 2179-84.

${ }^{15}$ Fletcher MS, Brinkley D, Dawson JL, Nunnerley $H$, Wheeler PG, Williams R. Treatment of high bile duct carcinoma by internal radiotherapy with Iridium-192 wire. Lancet 1981; ii: 172-4.

\section{Correction}

In the paper by Michael L Burr (1987, 41, 185-9) the first of the two references 32 in the text should relate to the following:

Weinberg EG, van Niekerk CH, Shore SC, Heese $\mathrm{H}$ de V, van Schalkwyk DJ. Prevalence of asthma. Lancet 1977; ii: 500. 